\title{
movimento
}

faculdade de educação - programa de pós-graduação em educação

universidade federal fluminense

issn 2359-3296

ano 3 número 5 - 2016

\section{CONSELHOS MUNICIPAIS DE EDUCAÇÃO EM SANTA CATARINA E NO PARANÁ: do pioneirismo ao lugar-comum nas tendências hegemônicas conservadoras}

\author{
Adolfo Ignacio Calderón ${ }^{1}$ \\ Donaldo Bello de Souza²
}

\section{RESUMO}

Este artigo se pauta na análise dos resultados de algumas investigações teóricoempíricas sobre o funcionamento institucional e sociopolítico dos Conselhos Municipais de Educação (CMEs) nos estados de Santa Catarina e do Paraná, publicados no período 1996-2010. Em termos conclusivos, confirma a hipótese inicialmente formulada de que o pioneirismo político-institucional desses estados, nos anos 1980, veio a dar lugar, a partir da década de 1990, a uma prática política conservadora, de caráter hegemônico, acenando para certa inércia e instrumentalização dos CMEs pelo Executivo Local.

Palavras-chave: Conselhos Municipais de Educação, Santa Catarina, Paraná

\section{ABSTRACT}

This paper is based on the analysis of the results of some theoretical-empirical research about the institutional and socio-political functioning of the Municipal Education Councils (CMEs) in the states of Santa Catarina and Paraná, published in the period 1996-2010. The article confirms the hypothesis initially formulated that the political-institutional

\footnotetext{
${ }^{1}$ Doutor em Ciências Sociais pela Pontifícia Universidade Católica de São Paulo (PUC-SP), com Pós-Doutorado em Ciências da Educação pela Universidade de Coimbra. Professor Titular do Programa de Pós-Graduação em Educação da Pontifícia Universidade Católica de Campinas (PUC-Campinas). Bolsista de Produtividade em Pesquisa do Conselho Nacional de Desenvolvimento Científico e Tecnológico (CNPq). E-mail: adolfo.ignacio@puccampinas.edu.br.

2 Doutor em Educação pela Universidade Federal do Rio de Janeiro (UFRJ), com Pós-Doutorado em Política e Administração da Educação pela Faculdade de Psicologia e de Ciências da Educação da Universidade de Lisboa. Professor Associado no Departamento de Políticas Públicas, Avaliação e Gestão da Educação (DEPAG) na Faculdade de Educação da Universidade do Estado do Rio de Janeiro (UERJ). Líder do Grupo de Pesquisa em Política e História da Educação Municipal junto ao CNPq. E-mail: donaldobello@gmail.com.
} 


\section{movimento}

faculdade de educação - programa de pós-graduação em educação

universidade federal fluminense issn 2359-3296

ano 3 número 5 - 2016

pioneering of these states, in the 1980s, came to be replaced, from the 1990s, by a conservative political practice, whith hegemonic character, which indicates a certain inertia and instrumentalization of CMEs by the Local Executive.

Keywords: Municipal Education Councils, Santa Catarina, Paraná.

\section{Introdução}

A partir da promulgação da Constituição Federal (CF) de 1988 (BRASIL, 1988), passou-se a observar a estruturação de novas redes associativas (GOHN, 2001; 1998) e canais de participação popular na esfera da gestão pública (LUCHMANN, 2007; MENDES, 2007; LAVALLE; HOUTZAGER; CASTELLO, 2006), com desenho institucional deliberativo (CUNHA; THEODORO, 2014; GURGEL; JUSTEN, 2013; OLIVEIRA; PEREIRA; OLIVEIRA, 2010), entre as quais a criação de Conselhos nas diversas áreas das políticas públicas. Esses Conselhos viriam a ser amparados por ampla base legal, assumindo diversos formatos e funções, sendo caracteristicamente compostos por representantes do poder público e da sociedade civil, a exemplo das iniciativas em torno da constituição dos Conselhos de Direitos, de Assistência Social, de Saúde, de Educação, entre outros (GOHN, 2001).

No campo da Educação Básica, em meio aos desafios postos pela Lei de Diretrizes e Bases da Educação Nacional (LDBEN) ㄲo 9.394, de 20 de dezembro de 1996 (BRASIL, 1996a) à implantação da gestão democrática no âmbito dos sistemas locais de educação, disseminam-se os Conselhos Escolares, os Conselhos de Classe e de Série, os Grêmios Estudantis, os Conselhos de Acompanhamento e Controle Social (CACS) e, especialmente, os Conselhos Municipais de Educação (CMEs) (SOUZA, 2013; 2008; 2006; VALLE; VASCONELOS, 2012; CALDERÓN, 2008; MARTINS, 2011; OLIVEIRA et al., 2006; SCHEINVAR; ALGEBAILE, 2005). 


\section{movimento \\ faculdade de educação - programa de pós-graduação em educação \\ universidade federal fluminense issn 2359-3296 \\ ano 3 número 5 - 2016}

Especificamente a respeito dos CMEs, em 2013 foi publicada a coletânea intitulada "Mapa dos Conselhos Municipais de Educação no Brasil" (SOUZA, 2013a), que trouxe à vista o exame sobre o funcionamento institucional e sociopolítico destes órgãos colegiados, em âmbito nacional. Trata-se de um estudo que tomou por base levantamento documental exaustivo em torno da produção teórico-empírica relativa a esses órgãos colegiados, publicada no Brasil no período 1996-2010, tendo operado com os resultados de investigações sobre 291 CMEs pertencentes a 12 estados $^{3}$ e ao Distrito Federal, englobando 6,6\% dos 4.403 CMEs existentes em 2009 no País (SOUZA, 2013b).

A apreciação global dos resultados dessas investigações veio a revelar problemas estruturais e conjunturais comuns entre os CMEs enfocados, relativos tanto à sua criação e implantação, quanto ao funcionamento institucional e sociopolítico. Tais problemas são apontados por Souza, Duarte e Oliveira (2013, p. 48) como decorrentes da "ausência de um projeto político de Estado (ao nível federal, estadual e local) voltado para a autonomização dos CMEs", o que tornaria esses órgãos "reféns das políticas de governo, comprometendo, por conseguinte, o ideário da gestão democrática da Educação Básica [...]" (SOUZA; DUARTE; OLIVEIRA, 2013, p. 48).

Dentre o conjunto dos nove estudos publicados na coletânea em questão (SOUZA, 2013a), que analisam a produção teórico-empírica sobre os CMEs nos nove estados aludidos, destaca-se o texto de Calderón \& Souza (2013) que considerou as pesquisas relativas aos CMEs pertencentes a dois Estados da Região Sul, a saber, Santa Catarina e Paraná. No primeiro caso, Estes autores

\footnotetext{
${ }^{3}$ Bahia, Espírito Santo, Mato Grosso do Sul, Minas Gerais, Pará, Paraíba, Paraná, Pernambuco, Rio de Janeiro, Rio Grande do Sul, Santa Catarina e São Paulo (SOUZA, 2013).
} 


\section{movimento}

faculdade de educação - programa de pós-graduação em educação

universidade federal fluminense issn 2359-3296

ano 3 número 5 - 2016

tomaram por base os resultados das investigações de Kleba et al. (2010) e Pierozan (2006), respectivamente relacionadas aos CMEs do município de Chapecó (Região Oeste do Estado) e de 32 localidades (72,7\% do total de 44) que compõem duas Associações Municipais do estado de Santa Catarina: a do Alto Uruguai Catarinense (AMAUC) e a do Alto Vale do Itajaí (AMAVI). No segundo caso, foram examinados os resultados de investigações relacionadas a dois CMEs do estado do Paraná, um localizado em meio urbano, de autoria de Moreschi (2010), e outro em região de características rurais, levado a efeito por Oliveira (2008), respectivamente enfocando os municípios de São José dos Pinhais (quinta maior área da Região Metropolitana de Curitiba) e de Ponta Grossa (localizado na Região dos Campos Gerais).

No âmbito do presente artigo, reedita-se o estudo efetuado por Calderón \& Souza (2013), contudo, atualizando os seus dados quantitativos, assim como promovendo o aperfeiçoamento das análises originalmente feitas e sua adaptação editorial a este conceituado periódico.

Grosso modo, defende-se a hipótese de que distante do pioneirismo e protagonismo político que se fez notar nos estados de Santa Catarina e do Paraná, especialmente na década de 1980 - no que tange à gestão democrática, por meio, entre outros aspectos, da eleição direta dos diretores de escola -, as investigações evocadas acenam para certas inércia e instrumentalização dos CMEs pelo Poder Executivo local, isto em sintonia com certas tendências conservadoras predominantes no cenário nacional mais amplo.

Para tanto, após esta introdução, em duas outras seções, discute-se alguns dos aspectos que marcaram o processo de descentralização da educação no Brasil, quer anteriormente à CF de 1988, quer a partir da sua promulgação. $\mathrm{Na}$ 


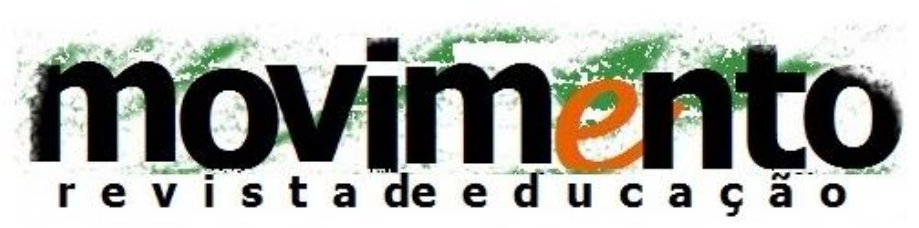

faculdade de educação - programa de pós-graduação em educação

universidade federal fluminense issn 2359-3296

ano 3 número 5 - 2016

sequencia, aborda-se a criação e implantação dos Sistemas Municipais de Ensino no País para, em outras duas seções, enfocar-se os CMEs nos estados de Santa Catarina e do Paraná e, com isto, evoluir-se para a seção conclusiva do artigo.

\section{Alguns aspectos da descentralização da educação anteriores à CF/1988}

A par da tradição histórica que marca o Brasil em termos da centralização das políticas públicas pelos governos centrais, desde a era colonial, passando pelo império até o início e o desabrochar da república - fosse, portanto, a Cora Portuguesa, o Regime Monárquico ou mesmo o Estado Republicano -, é possível afirmar que mais recentemente as especificidades das políticas centralizadoras implantadas durante o regime militar, nas décadas de 1960 e 1970, especialmente no campo social, podem ser tomadas como ponto de referência para o arranjo político-administrativo que se aprofundou e consolidou no país e que ainda se faz notar nos dias atuais (PERONI, 2003).

Conforme destacado por Arretche (1999), governadores e prefeitos das capitais brasileiras e de cerca de 150 cidades de médio e grande portes eram formalmente selecionados por meio de eleições indiretas, mas de fato, a priori, indicados pelo regime militar vigente. Naquele período, lembra a autora, o governo federal caracterizou-se pela centralização financeira e administrativa de programas como os relacionados ao reforço alimentar e de apoio à Educação Básica, que eram diretamente formulados, financiados e implementados por agências do governo federal, porém executados por estados e municípios. Como afirma Santos Filho (1992), a rígida separação entre órgão decisório e órgão 


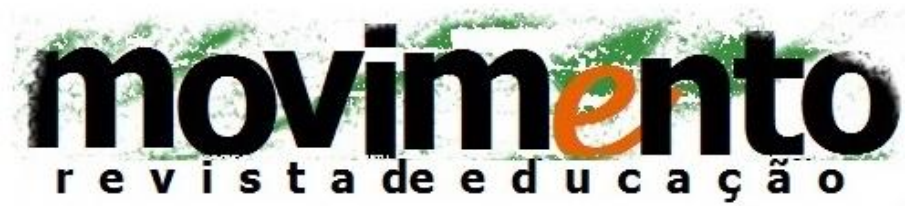 \\ faculdade de educação - programa de pós-graduação em educação \\ universidade federal fluminense issn 2359-3296 \\ ano 3 número 5 - 2016}

executor representou nitidamente o espírito positivista e tecnocrático dos militares e de seus tecnoburocratas, restando aos órgãos desconcentrados (cf. CASSASUS, 1995) a execução das decisões advindas das instâncias superiores.

Este padrão de atuação estatal veio a se constituir na realidade questionada por forças democráticas que emergiram ao longo das décadas de 1970 e 1980, no primeiro caso por meio dos chamados movimentos populares, pautados não somente pela luta por equipamentos sociais, como escolas e creches, mas também pelo seu controle e fiscalização por meio de Conselhos populares, enquanto que no segundo caso a partir da classe política eleita nos processos de restauração da democracia representativa do início dos anos 1980. Como bem assinala Barros \& Mendonça (1998), com as eleições diretas para governador, em 1982, deslanchou-se no País um novo processo de difusão de inovações em termos da gestão escolar, com variados graus e intensidades entre os sistemas estaduais de ensino. Trata-se de um processo que pode ser enquadrado como relativo à "democratização institucional" (SANTOS FILHO, 1992, p. 223), ou seja, à "democratização da gestão das instituições da sociedade" (SANTOS FILHO, 1992, p. 223).

Neste contexto de inovações da década de 1980, destacamos o pioneirismo dos estados de Santa Catarina e do Paraná na implantação do processo de eleição para diretores das escolas das redes públicas, isto como alternativa ao modelo tradicional de indicação para o desempenho deste cargo de vital importância para a gestão das unidades escolares, que há muito se realizava pela via da indicação política, em especial, pela Secretaria de Estado de Educação (SEE) ou por outros órgãos do poder público, mesmo à margem da constituição local dos Sistemas Municipais de Educação. 


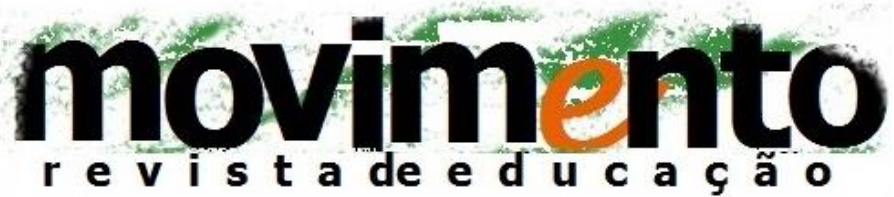

faculdade de educação - programa de pós-graduação em educação

universidade federal fluminense issn 2359-3296

ano 3 número 5 - 2016

No campo da descentralização das políticas educacionais, ou seja, em meio ao processo de partilha de poderes ${ }^{4}$, a adoção da eleição direta para diretores tornou-se, por exemplo, na visão de Mendonça (2001, p. 88), na forma "que melhor materializou a luta contra o clientelismo e o autoritarismo na administração da educação", apesar de ainda possuir uma série de limitações e problemas como o personalismo e a apropriação do cargo pelo diretor eleito.

A pesquisa intitulada "Mapeamento da descentralização da educação brasileira nas redes estaduais do ensino fundamental", promovida pelo Instituto de Pesquisa Econômica Aplicada (IPEA), do Ministério do Planejamento, Orçamento e Gestão (MP), elaborada por Parente \& Lück (1998), assinala que a eleição direta para escolha de diretores escolares teve início no ano de 1984, no estado do Paraná, logo após a realização de eleições para governadores estaduais, em 1982. Por sua vez, a pesquisa de Barros \& Mendonça (1998), intitulada "O impacto de três inovações institucionais na educação brasileira", também financiada pelo IPEA, reitera esta informação, acrescentando que, também de modo pioneiro, em 1986, o estado de Santa Catarina veio a implantar tal sistema de eleições ${ }^{5}$.

\footnotetext{
${ }^{4}$ Processo que se contrapõe ao simples deslocamento de atribuições, por exemplo, entre entes federados ou entre determinados órgãos e suas unidades, conceituado por Cassasus (1995) como relativo à desconcentração.

5 Este mesmo trabalho (BARROS; MENDONÇA, 1998) ressalta também que, na segunda metade dos anos 1980, esse mecanismo foi introduzido em mais três outros estados: Ceará (1985), Mato Grosso (1987) e Rio Grande do Norte (1989), tendo, durante os anos 1990, se estendido a mais outros quatro: Paraíba, Espírito Santo, Minas Gerais e Mato Grosso do Sul, em que pese o fato de ainda não se fazer notar em algumas outras redes estaduais. Por exemplo, no estado do Rio de Janeiro as eleições diretas para os diretores das escolas públicas da sua rede somente começaram a ser implantadas a partir de junho de 2016, após atendimento por parte do governo de uma das reivindicações do movimento estudantil "Ocupa" e dos professores, cuja greve durou mais de três meses (MENASCE, 2016).
} 


\section{$\operatorname{movim}_{\text {revistade educaço }}$}

faculdade de educação - programa de pós-graduação em educação

universidade federal fluminense issn 2359-3296

ano 3 número 5 - 2016

Em relação ao estado do Paraná, o estudo de Lima \& Viriato (2000) aponta que foi na gestão do governador José Richa (1983-1984) que se implantaram na área de educação as chamadas políticas de impacto, que se traduziam em eleições diretas para diretores de escola, na não obrigatoriedade de uniformes escolares e, em especial, na descentralização administrativa da SEE.

No tocante ao estado de Santa Catarina, as pesquisas de Santos Filho (1992) destacam também o seu pioneirismo em face desse processo de descentralização da gestão educacional, na medida em que o governo desse estado, embora do Partido Democrático Social (PDS), durante a gestão de Esperidião Amim (1983-1986), estimulou, entre outras atividades inovadoras, a implantação de um sistema de eleição direta dos diretores das escolas públicas e a criação de Conselhos Escolares compostos por representantes de professores, alunos e pais. Entretanto, o autor afirma que essas experiências foram progressivamente sendo erodidas na gestão do governo subsequente, por contradição pertencente a um partido mais progressista que o seu antecessor 6 .

Considerando os processos descentralizadores, no contexto de democratização até antes da CF/1988 (BRASIL, 1988), a mesma que consagrou a descentralização como principio norteador das políticas públicas no Brasil, podemos mencionar a existência de outras duas inovações no campo da administração pública, nas quais se constata o pioneirismo dos estados de Santa Catarina e do Paraná: a autonomia financeira, no sentido da existência de recursos para que a própria escola os gerencie, ao lado da implantação de Conselhos Escolares.

\footnotetext{
${ }^{6}$ Lima \& Viriato (2000) referem-se ao governador Pedro Ivo Maldaner (1987-1990) do Partido do Movimento Democrático Brasileiro (PMDB) que extinguiu a Comissão de Implantação do Plano Estadual de Educação (PEE), criado durante o mandato de seu antecessor. A respeito deste assunto, veja-se também Pierozan (2006).
} 


\section{movimento \\ faculdade de educação - programa de pós-graduação em educação \\ universidade federal fluminense issn 2359-3296 \\ ano 3 número 5 - 2016}

A respeito dessas inovações, o estudo de Barros \& Mendonça (1998) também aponta dados importantes, pois embora tradicionalmente as escolas limitavamse à eleição de suas prioridades, com as políticas de autonomia financeira, estas passam a gerenciar recursos financeiros, obviamente, dentro de determinadas restrições, como, por exemplo, o pagamento de pessoal. O primeiro estado a adotar este modelo foi o de Sergipe, em 1977, seguido de Santa Catarina, em 1980. Com as eleições de 1982, a transferência de recursos foi implantada em mais quatro estados: Bahia em 1982, Pernambuco em 1983, Paraná em 1983 e Goiás em 1984.

No que tange à implantação de Conselhos Escolares, Barros \& Mendonça (1998), destacam que estes órgãos - de natureza consultiva e deliberativa, responsáveis pela coordenação e avaliação das atividades pedagógicas, administrativas e financeiras das unidades escolares, declaradamente com a participação de professores, funcionários, pais, alunos e membros da comunidade - também ganhou impulso com as eleições para governador em 1982, sendo implantado, pioneiramente, entre 1983 e 1986, em quatro estados, sendo um deles o de Santa Catarina, em 19867.

No caso do estado do Paraná, é conveniente mencionar que a implantação dos Conselhos Escolares deu-se somente em 1991, após a CF/1988 (BRASIL, 1988). Analisando especificamente a implantação dos Conselhos nas escolas do Paraná, Martins (1998) enfoca o projeto "Construindo a Escola Cidadã", implantando durante o governo Requião (1991-1994), ressaltando a forma tumultuada como foram disseminados os Conselhos: com pressa, sem consulta

\footnotetext{
7 Os outros estados foram Minas Gerais (1983), Goiás (1984) e São Paulo (1985) (BARROS; MENDONÇA, 1998).
} 


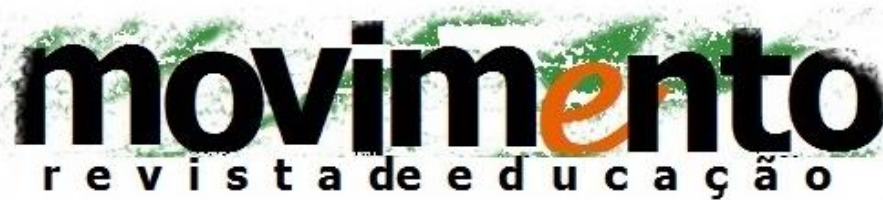

faculdade de educação - programa de pós-graduação em educação

universidade federal fluminense issn 2359-3296

ano 3 número 5 - 2016

à comunidade, com indicação dos membros pelos diretores sem processo eleitoral. Conforme afirmado pela autora, o processo foi atropelado pelo fato de a criação desses Conselhos ter condicionado a avaliação do desempenho docente para fins de ascensão na carreira. Em relação aos Conselhos Escolares, Lima \& Viriato (2000) fazem uma leitura semelhante à de Martins (1998) ao considerarem que sua atuação se restringe às normas disciplinares.

Sua eleição é viciada, sua atuação é controlada, suas deliberações não são significativas, perdem relevância em relação à Associação de Pais e Mestres (APMs) - entidade com caráter, historicamente, de cunho assistencial e voltada à cooperação financeira da escola (LIMA; VIRIATO, 2000, p. 10).

Para Martins (1998), os traços autoritários e centralistas da política educacional paranaense desta época vieram a potencializar os Conselhos Escolares desmobilizando as APMs, estas constituídas nos governos anteriores como "entidades auxiliares da escola, cujo objetivo precípuo é a integração entre as comunidades e os agentes escolares no desenvolvimento de atividades assistenciais e educativas" (MARTINS, 1998, p. 143) ${ }^{8}$.

\section{Alguns aspectos da descentralização da educação posteriores à CF/1988}

Conforme apontado em outros estudos nossos (SOUZA; FARIA, 2004), somente com a promulgação da $\mathrm{CF} / 1988$ a tese da descentralização da educação se tornou efetivamente lei, por meio do artigo 211 (BRASIL, 1988) que fixa, por ineditismo no Brasil, a organização dos sistemas de ensino entre a União, os

${ }^{8}$ É importante registrar que, ainda conforme os dados de Barros \& Mendonça (1998), no final dos anos 1980, o número de estados com Conselhos Escolares era idêntico ao observado no meio da década, isto é, apenas quatro, sendo que no início dos idos de 1990 presencia-se uma rápida difusão desta inovação, pois sete estados o implantaram entre 1991 e 1992. 


\section{movimento}

faculdade de educação - programa de pós-graduação em educação

universidade federal fluminense issn 2359-3296

ano 3 número 5 - 2016

estados, o Distrito Federal e os municípios pela via do chamado Regime de Colaboração, estabelecendo um novo paradigma para a efetivação do pacto federativo e, em particular, para a constituição dos Sistemas de Educação.

Contudo, a década de 1990 se caracterizou contraditória e um tanto paradoxal em relação ao princípio da descentralização das políticas educacionais, pois enquanto as políticas governamentais da década de 1980 se organizavam em torno da regulação de uma "racionalidade democrática", nos anos 1990 evidencia-se a emergência de uma "racionalidade financeira" (SAVIANI, 1999), implicando redução dos gastos públicos e do tamanho do Estado, assim como abertura do país ao capital financeiro internacional.

Diante da predominância da "racionalidade financeira", expressão das políticas neoliberais que passam a ser disseminadas enquanto solução para mais uma crise estrutural do modo de produção capitalista (SOUZA, 1996), o sentido da descentralização é ressignificado, traduzindo-se, na prática, no fenômeno da desconcentração. Nestes termos, Parente \& Lück (1998) recorrem aos estudos de Malpica (1994), entendendo por descentralização, do mesmo modo que Cassasus (1995), a transferência de competências para outros níveis de governo, de decisão e gestão com autonomia e personalidade jurídica própria, como federalização, regionalização, municipalização ou privatização, enquanto a desconcentração seria caracterizada pela delegação regulamentada da autoridade, ou seja, sujeita a diretrizes e normas, controle e prestação de contas a outros níveis de decisão e gestão, que permanecem política e administrativamente sujeitos e subordinados para a tomada de determinadas decisões administrativas e o assumir de responsabilidades correspondentes. 


\section{movimento \\ faculdade de educação - programa de pós-graduação em educação \\ universidade federal fluminense issn 2359-3296 \\ ano 3 número 5 - 2016}

A pesquisa de Parente \& Lück (1998) assinala ainda, em termos estaduais, a tendência ao final da década de 1980 da implementação de processos de descentralização e de desconcentração, ou seja, de delegação do poder decisório para as municipalidades, assim como a instituição da autonomia da escola nas áreas administrativa, pedagógica e financeira.

Já no âmbito federal, Souza \& Faria (2004) apontam para a manutenção da centralização do poder decisório na União, estabelecendo-se uma divisão técnica e política da gestão da Educação Básica, por meio da qual é rompida a figura solidária da colaboração que havia marcado, significativamente, o avanço democrático das novas relações no pacto federativo, tal qual constam na CF/1988 (BRASIL, 1988) e na LDBEN no 9.394/1996 (BRASIL, 1996a).

A partir desses marcos legais, a política de municipalização da rede de ensino de 1를 a $4^{\underline{a}}$ série do Ensino Fundamental, até 1994, somente irá ocorrer no estado do Paraná, e, posteriormente, com menor grau, no estado do Ceará (ARRETCHE, 1999). Esta autora atribui o êxito da municipalização no estado do Paraná devido ao fato de que no período 1987-1994 existia um programa deliberado de transferência da rede de ensino do estado para os municípios. Conforme Ribeiro et al. (1997), no início dos 1990, o governo do Paraná criou mecanismos para ampliar o processo de municipalização, concretamente criando o Protocolo de Intenções e o Termo Cooperativa de Parceria Educacional, estabelecendo, para tanto, a partilha de encargos entre o governo estadual e os municípios. Ribeiro et al. (1997) ressaltam ainda que, entre 1990 e 1992, 83\% dos municípios do Paraná municipalizaram a rede de $1^{\circ}$ ao $4^{\circ}$ ano do Ensino Fundamental. No entanto, convém ter presente a pesquisa de Lima \& Viriato (2000) que destaca que o processo de municipalização do Ensino Fundamental do estado do Paraná iniciou-se, em 1983, com a criação de 


\section{movimento \\ faculdade de educação - programa de pós-graduação em educação \\ universidade federal fluminense issn 2359-3296 \\ ano 3 número 5 - 2016}

convênios com as prefeituras municipais para a contratação de pessoal técnicoadministrativo, serviços gerais e professores, sendo contrapartida do município as obrigações contratuais e a administração de recursos e de profissionais.

No estado de Santa Catarina a pesquisa de Pierozan (2006) permite constatar que ocorreu um processo muito semelhante àquele vivenciado no estado do Paraná. Foi no governo de Wilson Kleinübing (1991-1994) que se efetivaram grande parte das propostas de municipalização do ensino, pois, à época, dos 293 municípios catarinenses, 231 aderiram à municipalização (aproximadamente $79 \%$ do total). Essa elevada adesão também foi resultado do pragmatismo das políticas indutoras à municipalização do governo estadual que, entre outras medidas, condicionou a liberação e repasse de verbas estaduais aos municípios, desde que os mesmos aderissem à proposta de descentralização. É conveniente registrar que apesar de o governo anterior, de Pedro Ivo Maldaner (1987-1990), ter criado políticas indutoras para que os municípios realmente viessem aplicar os $25 \%$ constitucionais de suas receitas na área da educação, dados estatísticos da época apontam que $90 \%$ dessas localidades não o realizavam. Diante deste fato, o Governo Estadual solicitou ao Tribunal de Contas (TC) para que rejeitasse as contas dos prefeitos que não realizavam os gastos constitucionais com educação em termos de Manutenção e Desenvolvimento do Ensino (MDE), proposta levada a efeito pelo TC (PIEROZAN, 2006). 


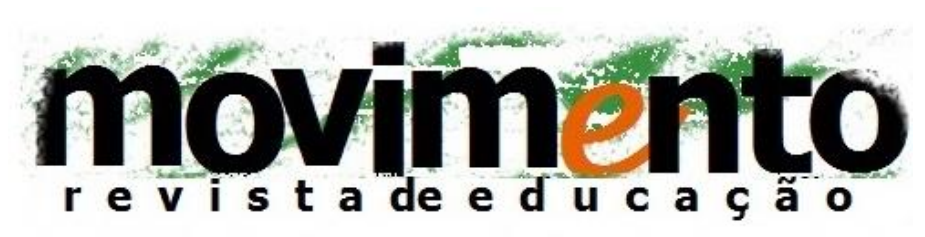

faculdade de educação - programa de pós-graduação em educação

universidade federal fluminense issn 2359-3296

ano 3 número 5 - 2016

\section{Criação e implantação dos Sistemas Municipais de Ensino}

No capítulo referente à educação, a CF/1988 estabeleceu as condições necessárias para que a LDBEN no 9.394/1996 (BRASIL, 1996a) viesse a regulamentar a criação dos Sistemas Municipais de Ensino. A partir da leitura do artigo 11, se conclui que esta lei determina para os municípios três opções: ou criam seu próprio sistema de ensino, ou se integram ao Sistema Estadual de Educação ou compõem com este um Sistema Único de Educação Básica.

Convém registrar que, conforme Saviani (1999, p. 124), "a definição clara da competência dos Municípios para instituir os seus Sistemas de Ensino próprios flui" da LDBEN e não da CF/1988. A Carta Magna, nos artigos 211 e 212 (BRASIL, 1988), aponta, portanto, princípios genéricos que acenam para a organização dos sistemas de ensino da União, dos estados, do Distrito Federal e dos municípios em regime de colaboração, bem como para a responsabilidade da União de prestar assistência técnica e financeira a estes entes federados para o desenvolvimento de seus sistemas de ensino.

De acordo com Sarmento (2005), o processo de implantação dos sistemas de ensino no Brasil vem se dando de certa forma ofuscado, isto devido à confusão gerada entre os processos de municipalização e a própria criação, via de regra, secundada, desses sistemas, tendo como pragmático elemento indutor a política do Fundo de Desenvolvimento do Ensino Fundamental e de Valorização do Magistério (FUNDEF), que vigorou no período 1996-2006 (BRASIL, 1996b), mais recentemente substituída pelo Fundo de Manutenção e Desenvolvimento da 


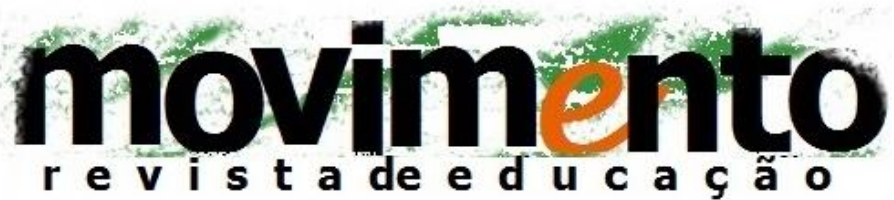

faculdade de educação - programa de pós-graduação em educação

universidade federal fluminense issn 2359-3296

ano 3 número 5 - 2016

Educação Básica e de Valorização dos Profissionais da Educação (FUNDEB), com vigência para o período 2006-2020:

A criação do FUNDEF, com a delimitação dos recursos e de sua aplicação, colocou o município ante a opção de perder recursos ou assumir o ensino fundamental. Essa realidade foi percebida como imposição e encontrou os municípios despreparados para assumirem as novas responsabilidades. A municipalização induzida ofuscou a compreensão do significado de se criar um Sistema Municipal de Ensino como opção autônoma na condução da política educacional. A pesquisa mostrou que um sistema único no âmbito municipal, com escolas responsáveis por todo o ensino fundamental, democraticamente administrado, é o ideal a ser alcançado (SARMENTO, 2005, p. 1.376).

Essa realidade evidencia que a criação de um Sistema Municipal de Ensino é muito mais do que uma política de transferência de responsabilidades de um ente federado para outro. Retomando Saviani (1999, p. 120), sistema de ensino significa "uma ordenação articulada dos vários elementos necessários à consecução dos objetivos educacionais preconizados para a população à qual se destina". Para esse autor, esses sistemas pressupõem planejamento, intencionalidade, organização e operacionalização segundo um plano de educação.

Complementando esta visão, Bordignon \& Pereira (2008, p. 14) sistematizam muito bem a relação que existe entre o Sistema Municipal de Ensino, o CME e o Plano Municipal de Educação (PME), ao afirmarem que o sistema constitui "o arcabouço legal maior de organização da educação no município", o Conselho seria o "fórum da gestão democrática e como órgão de consulta e de deliberação, com destaque para a função normativa", enquanto que o PME o "instrumento guia da gestão do sistema" (BORDIGNON; PEREIRA, 2008, p. 14). 


\section{movimento \\ faculdade de educação - programa de pós-graduação em educação \\ universidade federal fluminense issn 2359-3296 \\ ano 3 número 5 - 2016}

Assim, a implantação dos Sistemas Municipais de Ensino no Brasil apresenta quatro grandes desafios, quais sejam: a prevalência de um real regime de colaboração entre os entes federados, a criação dos Sistemas de Ensino e sua inclusão nas Leis Orgânicas Municipais (LOMs), a criação e real funcionamento dos CMEs e dos Conselhos de Acompanhamento e Controle Social (CACS), além de elaboração dos PMEs como efetivos "instrumentos de política educacional" (SAVIANI, 1999, p. 134).

Entretanto, deve-se destacar que a criação desses órgãos ou instrumentos de gestão não apresenta uma lógica sequencial de ações, na medida em que foram sendo criados a partir das múltiplas demandas e pressões, advindas principalmente do pragmatismo em face do atendimento de certas pressões do governo federal, conforme vimos sustentando. Como afirma Bordignon \& Pereira (2008), essa lógica propõe que a criação do Sistema Municipal de Ensino deveria preceder à criação do $\mathrm{CME}$, este último configurado enquanto órgão consultivo e deliberativo na gestão do sistema. Por sua vez, o PME deveria ser elaborado sob a liderança do CME que, ao definir diretrizes, objetivos e metas, se tornaria "a estrela guia" da gestão do sistema. No entanto, "o processo histórico instituiu antes os conselhos, e estes passaram a demandar a organização do sistema. É o caso da parte precedendo o todo. Em alguns casos, até os PMEs antecederam a organização do sistema" (BORDIGNON; PEREIRA, 2008, p. 12).

\section{Os CMEs no estado de Santa Catarina}

Até o momento da finalização/atualização deste artigo, os dados mais recentes apontam que, juntamente com o estado do Rio de Janeiro, o estado de Santa 


\section{$\operatorname{movim}_{\text {revistade educaço }}$}

faculdade de educação - programa de pós-graduação em educação

universidade federal fluminense issn 2359-3296

ano 3 número 5 - 2016

Catarina se caracteriza pelo fato de apresentar a totalidade dos seus municípios (293 localidades) com legislação que cria o CME (BRASIL, IBGE, 2015; 2012). Deste total, $91,2 \%$ expõem estrutura paritária, $89 \%$ são considerados deliberativos e 98\% haviam declarado não ter realizado reunião nos últimos 12 meses (BRASIL, IBGE, 2012) ${ }^{9}$. Esses dados quantitativos, obviamente, não revelam a real dinâmica e funcionamento desses CMEs.

Conforme sinalizado na seção introdutória deste artigo, para o exame qualitativo dos CMEs no estado de Santa Catarina considerou-se duas referências identificadas no levantamento documental realizado. Um primeiro estudo consiste na investigação levada a efeito pelo Grupo de Pesquisa em Políticas Públicas e Participação Social da Universidade Comunitária Regional de Chapecó (UNOCHAPECÓ) que, em paralelo ao exame dos Conselhos Municipais da Assistência Social (COMAS), dos Direitos da Criança e do Adolescente (CMDCA) e da Saúde (CMS) no município de Chapecó, cidade localizada na Região Oeste do estado, também examina o seu CME ${ }^{10}$ (KLEBA et al., 2010). Um segundo estudo remete à Dissertação de Mestrado de Pierozan (2006), defendida no Programa de Pós-Graduação da Universidade Federal do Paraná (UFPR), que objetiva a análise não de um único CME no estado, mas de

\footnotetext{
${ }^{9}$ De acordo com a Pesquisa de Informação Básicas Municipais (MUNIC), realizada pelo Instituto Brasileiro de Geografia e Estatística (IBGE), a coleta das informações do Questionário Básico utilizado foi realizada no período de julho a dezembro de 2011 (BRASIL, IBGE, 2012),

${ }^{10}$ A nomenclatura originalmente utilizada por Klebaet al. (2010) é CMED.
} 


\section{movimento}

faculdade de educação - programa de pós-graduação em educação

universidade federal fluminense issn 2359-3296

ano 3 número 5 - 2016

dois conjuntos de Conselhos pertencentes a duas Associações Municipais, a saber, a AMAUC $^{11}$ e a AMAVI ${ }^{12}$.

O trabalho de Klebaet al. (2010) que, conforme acima assinalado, abarcou, além do CME, outros Conselhos do município de Chapecó, se caracteriza descritivo, pautado na aplicação de questionários semi-estruturados junto aos membros desses Conselhos, na análise documental e também na coleta de dados via observações e por meio de encontros apoiados na técnica de grupo foca. Visa à análise da problemática do controle social no funcionamento daqueles órgãos colegiados, inclusive sob enfoque comparativo.

Klebaet al. (2010) consideram, a priori, que os conselhos gestores consistem em espaços de exercício de cidadania, implicando necessidade de dinamizar a criação e o fortalecimento de canais e processos de diálogo com os diferentes atores sociais locais. No caso do $\mathrm{CME}^{13}$, focam suas análises no exercício das competências deliberativa, fiscalizadora, normativa, de assessoramento e de comunicação, além de considerarem outras atribuições específicas.

Embora os autores reconheçam que "O papel deliberativo tem sido apontado pela própria legislação como uma das principais funções dos conselhos gestores" (KLEBA et al., 2010, p. 796), no caso do CME de Chapecó vem

11 A AMAUC é composta pelos seguintes municípios: Alto Bela Vista, Arabutã, Arvoredo, Concórdia, Ipira, Ipumirim, Irani, Itá, Jaborá, Lindóia do Sul, Paial, Peritiba, Piratuba, Presidente Castello Branco, Seara e Xavantina. Disponível em: <http://www.amauc.org.br/> Acesso em 16 jul. 2012.

12 A AMAVI é composta pelos seguintes municípios:Agrolândia, Agronômica, Atalanta, Aurora, Braço do Trombudo, Chapadão do Lageado, Dona Emma, Ibirama, Imbuia, Ituporanga, José Boiteux, Laurentino, Lontras, Mirim Doce, Petrolândia, Pouso Redondo, Presidente Getúlio, Presidente Nereu, Rio do Campo, Rio do Oeste, Rio do Sul, Salete, Santa Terezinha, Taió, Trombudo Central, Vidal Ramos, Vitor Meireles e Witmarsum. Disponível em <http://www.amavi.org.br/> Acesso em: 16 jul. 2012.

${ }^{13}$ Originalmente, Klebaet al. (2010) denominam o CME de Chapecó como COMED. 


\section{$\operatorname{movim}_{\text {revistade educaço }}$}

faculdade de educação - programa de pós-graduação em educação

universidade federal fluminense issn 2359-3296

ano 3 número 5 - 2016

sobressaindo a competência fiscalizadora, com atribuições, por exemplo, de avaliação das experiências pedagógicas da rede, aspecto questionando pelos pesquisadores em face da pluralidade das perspectivas pedagógicas que podem servir a tal finalidade. A um só tempo, os autores identificam que os processos de normatização da política de educação, do funcionamento do Sistema Municipal de Ensino, das formas de organização e aproveitamento escolar e da transferência de alunos consistem numa das atribuições igualmente de relevo deste CME, em especial se comparada às ações consultivas que esbarram na problemática da capacitação dos conselheiros para tal finalidade, sobretudo no âmbito orçamentário, ou então comunicativas:

Sendo estratégia essencial na promoção da democracia participativa, o exercício do diálogo constitui-se também em desafio aos conselheiros como interlocutores das entidades que estes representam. Neste sentido, os conselheiros em Chapecó mostram-se preocupados em relação a pouca capacidade em efetivar seu papel de mediador enquanto representantes de entidades [...] (KLEBA et al., 2010, p. 800).

De modo conclusivo, Kleba et al. (2010) postulam que os Conselhos estudados, incluindo-se o CME, expõem uma elevada sobrecarga de atribuições de cunho burocrático, isto em detrimento da realização de discussões que poderiam favorecer sua constituição numa ambiência democrática de debate, tornando viável "que atores sociais com diferentes interesses dialoguem sobre concepções e projetos e aprendam a consensuar em favor de interesses coletivos" (KLEBA et al., 2010, p. 801). A um só tempo, esses autores chamam a atenção para os diversos problemas que decorrem das limitações postas a uma participação sociopolítica mais ativa, como o caráter voluntário e não profissional dos conselheiros, o pouco tempo destinado aos encontros e a ausência de infraestrutura física e logística voltada à sua realização, aspectos 


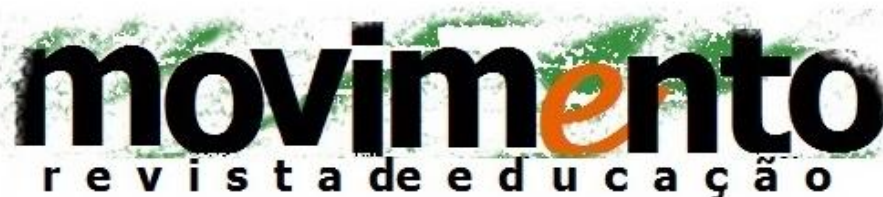

faculdade de educação - programa de pós-graduação em educação

universidade federal fluminense

issn 2359-3296

ano 3 número 5 - 2016

que igualmente contribuem para uma baixa autonomia desses órgãos colegiados na gestão local, neste caso na área da educação.

Já o estudo de Pierozan (2006) ${ }^{14}$, embora não estabelecendo generalizações que abarquem outras classes de Conselhos locais - a exemplo das análises levadas a efeito por Kleba et al. (2010) -, integra exame sobre $32(72,7 \%)$ dos 44 municípios pertencentes às duas Associações Municipais cujos CMEs foram estudados - à época, AMAUC, com 16 localidades, e AMAVI, com 28 -, mesmo levando em conta que se tratam de realidades distintas, uma vez que englobam territórios localizados em Regiões Metropolitanas (RMs), na capital e no interior. Procurando demarcar as possibilidades e limites da atuação democrática destes órgãos, o autor assinala que as associações de Municípios de Santa Catarina são formadas a partir de certas proximidades geográficas "e existem como forma de impulsionar o desenvolvimento da região por meio da ajuda mútua, nos assuntos de interesse das administrações municipais" (PIEROZAN, 2006, p. 154), havendo, por época da realização do estudo, cerca de 21 dessas Associações no estado que, em seu conjunto, totalizam 292 municípios, além de mais uma localidade não vinculada a essas instâncias ${ }^{15}$.

De modo geral, Pierozan (2006) busca discorrer sobre os objetivos da constituição desses CMEs, cuja implementação começou a ser observada na AMAUC, em 1991, no município de Presidente Castelo Branco, e na AMAVI, em

\footnotetext{
${ }^{14}$ Veja-se também Pierozan \& Gonçalves (2006).

${ }^{15} \mathrm{O}$ autor chama atenção para a escassez de informações a respeito do processo de descentralização da educação via municipalização no Estado de Santa Catarina, destacando a importância para o desenvolvimento de pesquisas que apontem a "composição do ensino público municipal" (PIEROZAN, 2006, p. 212), e que indiquem "em que momento da história teve início o ensino municipal realmente público e gratuito, quais os caminhos que os municípios tiveram que percorrer (entraves/dificuldades) para organizar seu sistema de ensino, e se realmente após a constituição dos Sistemas Municipais, a educação apresentou avanços mais democráticos" (PIEROZAN, 2006, p. 154).
} 


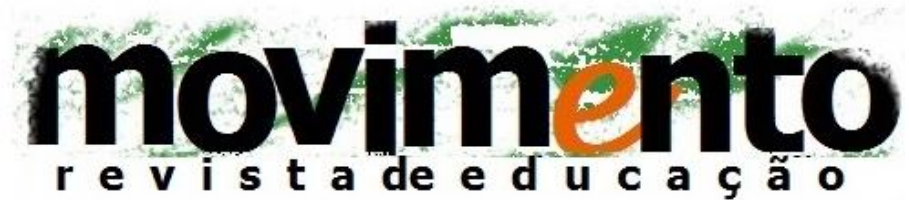 \\ faculdade de educação - programa de pós-graduação em educação \\ universidade federal fluminense issn 2359-3296 \\ ano 3 número 5 - 2016}

2001, no município de Trombudo, com organização paulatina dos Sistemas Municipais de Ensino ao longo do período 1997-2004. Em paralelo, o autor procura demarcar os avanços decorrentes da implantação desses CMEs, sua estrutura colegiada, a forma pelo qual veio se dando a escolha dos seus presidentes, o tempo de mandato e sobre as principais atribuições que esses órgãos colegiados passam a assumir. Para tanto, Pierozan (2006) se utilizou da aplicação de questionários, entrevistas semi-estruturadas, observações e análise documental.

Dentre o conjunto de problemas identificados no funcionamento institucional e sociopolítico dos Conselhos alvo da pesquisa de Pierozan (2006), assume centralidade o comprometimento da autonomia desses órgãos em função das tendências: de os Secretários Municipais de Educação acumularem sua presidência, de haverem dificuldades relacionadas ao conhecimento necessário para o desempenho das funções conselheiras, de ausência de infraestrutura adequada ao funcionamento dos CMEs, de alguns desses órgãos possuírem quantitativo insuficiente de componentes e de entidades/organismos que representam, além de não possuírem visibilidade pública, neste último caso intensificando a dependência em relação tanto à SME, quanto em relação ao Conselho Estadual de Educação (CEE). Em termos gerais, o autor sinaliza que a grande maioria dos municípios estudados expõem "dificuldades, do ponto de vista da competência técnica e compromisso político, o que dificulta sobremaneira a sua implementação [do CME]" (PIEROZAN, 2006, p. 211).

Entretanto, para Pierozan (2006, p. 209), a questão da autonomia é utilizada como "um fator que se usa para justificar a descentralização do ensino, uma vez que a ampliação de matrículas na rede municipal, no período posterior a criação 


\section{$\operatorname{movim}_{\text {revistade educąis }}$}

faculdade de educação - programa de pós-graduação em educação

universidade federal fluminense issn 2359-3296

ano 3 número 5 - 2016

de Conselhos e Sistemas", passou a exprimir a transferências de encargos relacionados ao Ensino Fundamental para os municípios, seguindo-se

[...] uma orientação básica na confeç̧ão da legislação, derivada da participação da UNDIME/SC [União Nacional dos Dirigentes Municipais de Educação], por meio de sua diretoria estadual, que foi a grande responsável pelo 'boom' de criação de conselhos, ou mesmo desta nova caracterização que eles passaram a ter, já no final da década de 1990, início dos anos 2000" (PIEROZAN, 2006, p. 209).

O autor entende que a criação dos CMEs na AMAUC e na AMAVI, apesar de não necessariamente implicar avanços, expõem possibilidades de exercício de uma gestão democrática participativa, evidenciando que, mesmo em face dos problemas identificados, são muitos os esforços na efetivação de experiências de caráter democrático naquelas regiões, especialmente em termos do envolvimento da população local no processo participativo dos CMEs.

\section{Os CMEs no estado do Paraná}

No que se refere ao estado de Paraná, os dados mais recentes apontam que dos 399 municípios paranaenses $75,4 \%$ apresentam legislação que cria o CME, sendo que apenas $69,2 \%$ indicam possuir estrutura paritária (BRASIL, IBGE, 2015). Em 2011, 70\% dos municípios com CME apresentavam função deliberativa e $83 \%$ chegaram a realizar reunião nos 12 meses declarados na pesquisa (BRASIL, IBGE, 2012) ${ }^{16}$.

${ }^{16}$ De acordo com a MUNIC/IBGE, a coleta das informações do Questionário Básico utilizado foi realizada no período de julho a dezembro de 2011 (BRASIL, IBGE, 2012). 


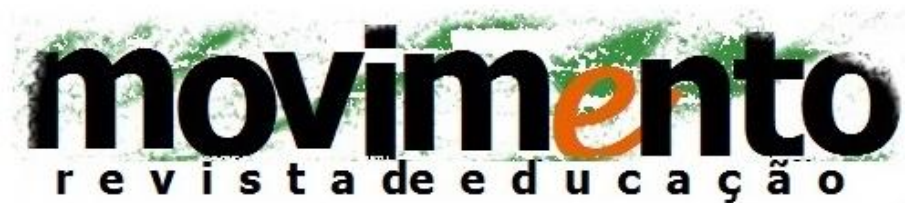 \\ faculdade de educação - programa de pós-graduação em educação \\ universidade federal fluminense issn 2359-3296 \\ ano 3 número 5 - 2016}

Para obter elementos que ajudem a compreender o real funcionamento desses conselhos, dois estudos foram identificados no levantamento documental realizado, mencionado na introdução deste artigo, ambos concernentes à realização de Dissertações de Mestrado, expondo contextos diferenciados nos e pelos quais os CMEs enfocados são criados - caracteristicamente o urbano e o rural -, mas que, do ponto de vista do conjunto amplo de problemas que marcam o funcionamento desses órgãos colegiados, sugerem significativa confluência de desafios institucionais e sociopolíticos. Um primeiro trabalho, realizado na esfera do Programa de Pós-graduação em Educação da Universidade Tuiuti do Paraná (UTP), refere-se ao CME de São José dos Pinhais (MORESCHI, 2010), município que consiste na quinta maior área da RM de Curitiba e que traz à vista um dos maiores índices de crescimento econômico do estado, consistindo no terceiro maior polo automotivo do país ${ }^{17}$. Já o segundo estudo, defendido no âmbito do Programa de Pós-Graduação em Educação da Universidade Estadual de Ponta Grossa (UEPG), remete ao CME de Ponta Grossa (OLIVEIRA, 2008), município do Segundo Planalto Paranaense, localizado na Região dos Campos Gerais, caracterizando-se, grosso modo, pelos seus atrativos turísticos e culturais. ${ }^{18}$

No primeiro caso, Moreschi (2010) tomou por referente dados secundários, concernentes a algumas pesquisas que enfocaram os CMEs de Ponta Grossa, no Paraná; Juiz de Fora, em Minas Gerais; Recife, em Pernambuco; Campinas, em São Paulo e, ainda, Serra, no Espírito Santo, de modo a verificar se tais cenários se aproximam daquele investigado, qual seja, o relativo ao CME de São

\footnotetext{
17 Veja-se Prefeitura de São José dos Pinhais. Disponível em: <http://www.sjp.pr.gov.br> Acesso em 16 jul. 2012.

${ }_{18}$ Veja-se Prefeitura de Ponta Grossa. Disponível em: <http://www.pg.pr.gov.br/> Acesso em: 16 jul. 2012.
} 


\section{movimento \\ faculdade de educação - programa de pós-graduação em educação \\ universidade federal fluminense issn 2359-3296 \\ ano 3 número 5 - 2016}

José dos Pinhais, isto sob perspectiva descritiva, exploratória e comparada, tomando por base a análise documental e entrevistas junto aos conselheiros deste órgão.

Conforme assinala o autor, o CME de Ponta Grossa "foi criado por meio da Lei [Municipal] no 02/93 com a finalidade de cooperar na elaboração do Plano Municipal de Educação e assessorar o Executivo nos assuntos ligados à educação" (MORESCHI, 2010, p. 78). Ao longo do período 1997-2010, esta lei sofreu uma "série de adaptações devido às mudanças conjunturais, na tentativa de agradar ou atender aos diversos atores sociais do momento" (MORESCHI, 2010, p. 83), que se estendem da definição quantitativa de sua composição, natureza das representações e estrutura interna, passando pela pormenorização das atribuições e do Regimento interno, culminando, por exemplo, em 2004, na sua reconfiguração para uma instância de maior autonomia em relação ao Poder Executivo local (embora transitória). Neste momento, Moreschi (2010) destaca que ocorre a ampliação do escopo de atuação do Conselho, agora também se responsabilizando pelo estabelecimento de normas complementares às nacionais e pelo credenciamento dos estabelecimentos de ensino locais, a par das atividades de assessoramento que até então serviam à caracterização da sua relação junto àquela esfera de poder.

A partir das análises levadas a efeito, Moreschi (2010) busca identificar algumas tendências relacionadas à composição, capacitação, tutela, autonomia e controle social, infraestrutura e funcionamento relativos ao CME de São José dos Pinhais, de modo a delinear o seu perfil em face de problemas similares igualmente identificados em CMEs dos outros estados anteriormente mencionados, que podem aqui ser resumidos do seguinte modo: i) a não paridade de representação entre o Poder Público e a Sociedade Civil, com 


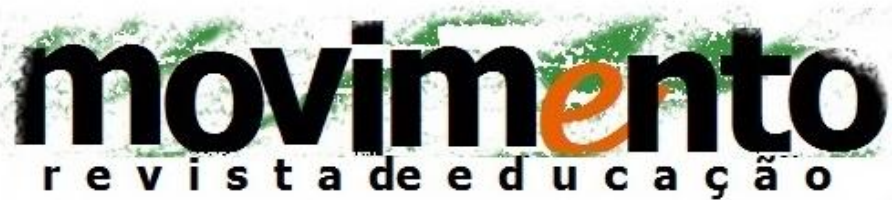

faculdade de educação - programa de pós-graduação em educação

universidade federal fluminense issn 2359-3296

ano 3 número 5 - 2016

prevalência de membros do primeiro segmento e, com isto, comprometimento da autonomia do órgão colegiado; ii) a indicação da presidência do Conselho pelo Poder Executivo e não pela via de eleição entre os seus pares; iii) a incipiência nas ações de capacitação dos conselheiros; iv) a não observância do Poder Executivo em relação às decisões do Conselho; v) a ausência de infraestrutura (instalações e logística) adequada ao funcionamento do CME; e, ainda, vi) a tendência acentuada de funcionamento do Conselho em torno de ações credencialistas e consultivas, em detrimento, por exemplo, de competências de cunho normativo, o que, para este autor, significa que o Conselho tende a se configurar enquanto órgão tipicamente de assessoramento da SME.

Em termos gerais, Moreschi (2010) associa grande parte dos problemas identificados no funcionamento institucional e sociopolítico dos CMEs, em especial no que remete ao de São José dos Pinhais, à ausência de leis federais que sirvam à definição da composição, atribuições e funcionamento desses órgãos, ou seja, à sua regulação, a exemplo do que acontece com os Conselhos do FUNDEB:

Sem dúvida alguma, a instituição de CMEs por meio de lei municipal não garante o pleno funcionamento desta organização, dificultando o desempenho de suas atribuições, tendo em vista que sua autonomia está nas mãos do Executivo municipal. Os CMEs acabam tornando-se meros órgãos legitimadores das políticas locais esvaziadas de participação, com sua existência dependendo da boa vontade do governante de turno (MORESCHI, 2010, p. 101).

Por sua vez. a pesquisa de Oliveira (2008), igualmente alicerçada na coleta de dados via análise documental e entrevistas, mas agora incluindo processos de observação, visou examinar a criação, estrutura, funcionamento e possíveis 


\section{movimento \\ faculdade de educação - programa de pós-graduação em educação \\ universidade federal fluminense issn 2359-3296 \\ ano 3 número 5 - 2016}

contribuições do CME de Ponta Grossa para a democratização do processo decisório na gestão da educação local.

Segundo Oliveira (2008, p. 95), a criação do CME de Ponta Grossa, que foi "aprovada pela Câmara Municipal no dia 11 de abril de 1995 (Lei n 5172)", ocorreu, de um lado, com base em discussões realizadas a partir de uma lei de criação do CME de um determinado município do estado de São Paulo, sob a alegação de que no estado do Paraná não havia lei semelhante que pudesse vir a subsidiar sua elaboração, e, de outro, com o apoio de docentes da Faculdade de Educação da Universidade Estadual de Ponta Grossa (UEPG), isto em meio à resistência do Poder Executivo em se dispor a compartilhar o poder político local junto a este órgão colegiado. Apesar disto, o autor chama a atenção para o fato de que a criação desse Conselho "surgiu mais pela iniciativa individual de um vereador oriundo da área da saúde e filiado a um partido considerado conservador [...]" (OLIVEIRA, 2008, p. 95) e não necessariamente em decorrência "de um processo de organização da comunidade, amadurecimento do processo democrático ou da proposição do Estado" (OLIVEIRA, 2008, p. 95).

Do mesmo modo que o CME de São José dos Pinhais, o de Ponta Grossa irá passar por diversas transformações, via expedição de leis e decretos, que irão impactar, em especial, o tipo de competência que caracteristicamente exercerá ao longo dos anos. Assim, de 1995 a 2002 preponderarão ações consultivas, enquanto que a partir desta última data, justo quando o Sistema Municipal de Ensino é criado, e até o ano de 2007, passa-se a observar o exercício da competência normativa - embora tal atribuição estivesse originalmente prevista na lei de criação do Conselho -, tendo significativamente aumentado a responsabilidade deste órgão, "pois passou a ser a maior autoridade em educação no Município" (OLIVEIRA, 2008, p. 113). 


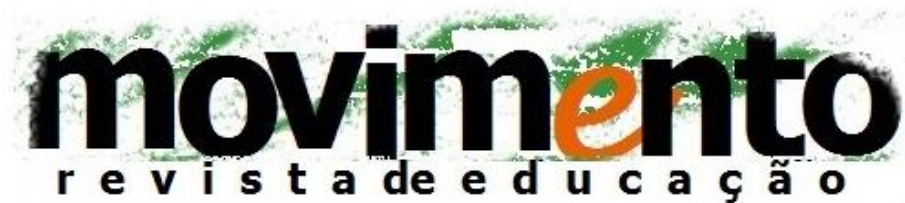 \\ faculdade de educação - programa de pós-graduação em educação \\ universidade federal fluminense issn 2359-3296 \\ ano 3 número 5 - 2016}

Embora sem negar o potencial e importância dos Conselhos em questão na gestão local, especialmente como uma das formas de garantia dos direitos sociais e de participação da sociedade civil, em particular na área da educação, Oliveira (2008, p. 161) destaca que o CME de Ponta Grossa "tem cumprido mais um papel legitimador das políticas educacionais emanadas da Secretaria Municipal de Educação do que propriamente um espaço de luta pela ampliação do direito à educação [...]". Destaca, ainda: i) a fragilidade das contribuições do Conselho no processo decisório-democrático, isto em função da ausência de discussões de maior intensidade em torno das demandas educacionais e decisões governamentais; ii) a ausência de infraestrutura própria e de autonomia administrativa e financeira, de modo a tornar o CME mais independente da SME; iii) o absenteísmo e a falta de clareza pelos membros conselheiros em torno do papel a ser exercido pelo órgão assim como desconhecimento da comunidade acerca de sua finalidade; aspectos salientados pelo autor como passíveis de serem identificados em diversos outros CMEs do país.

Por outro lado, Oliveira (2008) demarca algumas dimensões consideradas positivas sobre o funcionamento institucional e sociopolítico do CME de Ponta Grossa, como, por exemplo, a intensificação das competências deliberativas e normativas após a criação do Sistema Municipal de Ensino. Todavia, o autor não se furta à indicação de recomendações que visam à superação das limitações e problemas também identificados pela pesquisa, como, por exemplo: intensificação da aproximação do Conselho em relação à comunidade, maiores investimentos na formação dos conselheiros, aprofundamento da luta em torno da conquista de sua autonomização, interação com outros Conselhos da área de educação e indicações de conselheiros efetivamente comprometidos com 


\section{movimento \\ faculdade de educação - programa de pós-graduação em educação \\ universidade federal fluminense issn 2359-3296 \\ ano 3 número 5 - 2016}

causas sociais pelas diversas entidades que se fazem representar neste órgão colegiado.

Conforme pode ser observado, em que pesem as especificidades estruturais e conjunturais entre os CMEs de São José dos Pinhais (MORESCHI, 2010) e de Ponta Grossa (OLIVEIRA, 2008), sobretudo do ponto de vista territorial - 0 primeiro, tipicamente metropolitano, enquanto que o segundo de características rurais -, os problemas que marcam a autonomia relativa destes órgãos colegiados no estado do Paraná frente aos respectivos Poderes Executivos locais assumem relevo nas análises realizadas por ambos os autores, sugerindo que o funcionamento institucional e sociopolítico destes CMEs encontra-se comprometido, em especial se ponderado sua possível contribuição para a consolidação da proclamada gestão democrática da educação. Sobre este último aspecto, cabe ressaltar a pouca importância atribuída por ambos os estudos ao exame dos graus e níveis da participação sociopolítica (cf.GOHN, 2001; BORDENAVE, 1994) no interior dos Conselhos estudados, já que consistem, de fato, em importantes mediações para a construção processual de práticas de gestão ditas democráticas.

\section{Conclusões}

O estudo realizado, no que tange à descentralização das políticas educacionais de Santa Catarina e do Paraná, a partir das fontes teórico-empíricas já caracterizadas, permite constatar a centralidade das mudanças dos contextos socioeconômicos e políticos, bem como da dinâmica dos diversos atores do cenário educacional a partir da passagem e entrelaçamento que se deu entre a 


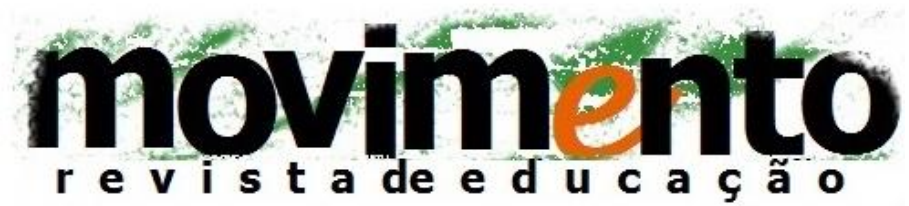 \\ faculdade de educação - programa de pós-graduação em educação \\ universidade federal fluminense issn 2359-3296 \\ ano 3 número 5 - 2016}

racionalidade democrática predominante na década de 1980 e a racionalidade econômica, esta última própria dos anos de 1990, no calor das políticas de ajuste fiscal de orientação neoliberal.

Da mesma forma, no contexto da chamada democratização institucional, isto é, das pressões por maior participação e intervenção da sociedade na gestão pública, tentamos demonstrar que Santa Catarina e Paraná foram estados da federação que se destacaram pelo pioneirismo no que tange à constituição das eleições para diretores, à autonomia financeira da escola e à implantação de Colegiados ou Conselhos Escolares. Esse pioneirismo ganhou importância em termos heurísticos na medida em que se criou um contraponto ao loteamento dos cargos públicos como estratégia de barganha política. Da mesma forma, com as políticas que fortaleciam a autonomia da escola, via a gestão de recursos financeiros, acenou-se para uma ruptura com o centralismo gerencial, enquanto modelo de gestão, consolidado durante os anos do regime militar.

$\mathrm{Na}$ hipótese que tentamos aqui sustentar, fica explícita a metamorfose ocorrida na atuação política dos diversos atores do cenário educacional dos estados estudados, na medida em que o pioneirismo dos anos de 1980 deu espaço a uma prática política que sinaliza a uma tendência hegemônica relativa a certa inércia e instrumentalização dos CMEs pelo Executivo Local, com fortes impactos no funcionamento institucional e sociopolítico desses órgãos.

As realidades ora estudadas e constatadas desafiam aos pesquisadores das políticas públicas na medida em que a instrumentalização dos CMEs pela política conservadora, baseada no patrimonialismo e na cultura tutelar, tornou-se uma realidade inclusive em municípios pertencentes a estados que possuem uma tradição e cultura maior em termos participativos. Daí fortalece-se a tese de que 


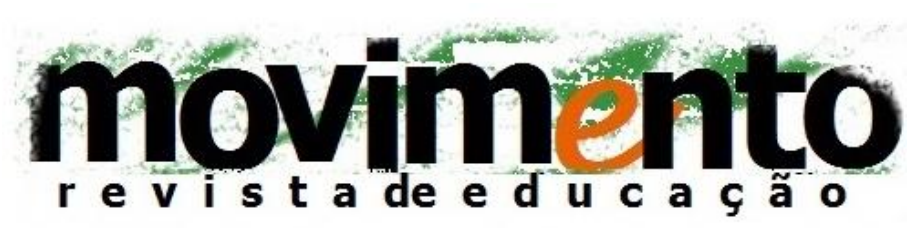

faculdade de educação - programa de pós-graduação em educação

universidade federal fluminense issn 2359-3296

ano 3 número 5 - 2016

os CMEs foram capturados por um projeto de modernização contemporânea de cunho conservador, cujo futuro depende menos de um ordenamento jurídico que venha a ser emanado pelo Governo Federal, e muito mais em função da tomada de consciência de seus membros acerca dos processos políticos que marcam, na sua negatividade, ou deveria marcar, na sua positividade, estes órgãos colegiados no país, em particular nos municípios-alvo das pesquisas que aqui se tomaram por referência analítica.

O fato de Santa Catarina despontar entre os estados brasileiros como aquele que possui a totalidade dos seus municípios com legislação específica que cria os CMEs, enquanto, no outro extremo, o Paraná com $69,2 \%$, pode gerar certo otimismo sociológico no analista desatento. Conforme visto, o estudo realizado demonstra que essa expressiva diferença existente entre Santa Catarina e Paraná, no que tange ao percentual de municípios com legislação que cria os CMEs, acaba se diluindo a partir de realidades comuns no campo da operacionalização institucional e sociopolítica desses Conselhos, o que compromete o funcionamento destes espaços de participação, teoricamente direcionados para a vivência e concretização da gestão democrática da educação enquanto princípio constitucional.

\section{Referências}

ARRETCHE, Marta. Políticas sociais no Brasil: descentralização em um Estado Federativo. Revista Brasileira de Ciências Sociais, São Paulo, v. 14, n. 40, p. 111-141, 1999. 


\section{movimento}

faculdade de educação - programa de pós-graduação em educação

universidade federal fluminense issn 2359-3296

ano 3 número 5 - 2016

BARROS, Ricardo Paes de; MENDONÇA, Rosane. O impacto de três inovações institucionais na educação brasileira. Rio de Janeiro: IPEA, jun. 1998 (Texto Para Discussão, 566).

BORDENAVE, Juan E. Díaz. O que é participação. 8. ed. São Paulo: Brasiliense, 1994.

BORDIGNON, Genuíno; PEREIRA, Álvaro de Pádua. Perfil dos Conselhos Municipais de Educação 2007. Brasília, DF: MEC/SEB, 2008.

BRASIL. Constituição (1988). Constituição da República Federativa do Brasil. Diário Oficial [da] República Federativa do Brasil. Brasília, DF, 5 out. 1988.

. Instituto Brasileiro de Geografia e Estatística. Pesquisa de informações básicas municipais: perfil dos municípios brasileiros2011. Rio de Janeiro: IBGE, 2012.

Instituto Brasileiro de Geografia e Estatística. Pesquisa de informações básicas municipais / Pesquisa de informações básicas estaduais: perfil dos estados e dos municípios brasileiros 2014. Rio de Janeiro: IBGE, 2015.

. Lei no 11.494, de 20 de junho de 2007. Regulamenta o Fundo de Manutenção e Desenvolvimento da Educação Básica e de Valorização dos Profissionais da Educação - FUNDEB, de que trata o art. 60 do Ato das Disposições Constitucionais Transitórias; altera a Lei no 10.195, de 14 de fevereiro de 2001; revoga dispositivos das Leis nos 9.424, de 24 de dezembro de 1996, 10.880, de 9 de junho de 2004, e 10.845, de 5 de março de 2004; e dá outras providências. Diário Oficial da União [da] República Federativa do Brasil. Brasília, DF. 21 jun. 2007.

. Lei no 9.394, de 20 de dezembro de 1996. Estabelece as Diretrizes e Bases da Educação Nacional. Diário Oficial [da] República Federativa do Brasil, Brasília, DF, 23 dez. 1996a.

. Lei no 9.424, de 24 de dezembro de 1996. Dispõe sobre o Fundo de Manutenção e Desenvolvimento do Ensino Fundamental e de Valorização do Magistério, na forma prevista no art. $60, \S 7^{\circ}$, do Ato das Disposições Constitucionais Transitórias e dá outras providências. Diário Oficial da União [da] República Federativa do Brasil, Brasília, DF, 26 dez. 1996b.

CALDERÓN, Adolfo Ignacio. Conselhos municipais: representação, cooptação e modernização da política patrimonialista. In: SOUZA, Donaldo Bello de. (Org.). 


\section{movimento \\ faculdade de educação - programa de pós-graduação em educação \\ universidade federal fluminense issn 2359-3296 \\ ano 3 número 5 - 2016}

Conselhos municipais e controle social da educação: descentralização, participação e cidadania. São Paulo: Xamã, 2008, p. 169-189.

CALDERÓN, Adolfo Ignacio; SOUZA, Donaldo Bello de. CMEs nos Estados de Santa Catarina e do Paraná:do pioneirismo ao lugar comum das tendências hegemônicas. In: SOUZA, Donaldo Bello de (Org.). Mapa dos Conselhos Municipais de Educação no Brasil. São Paulo: Loyola, 2013, p. 187-208.

CASSASUS, Juan. Tarefas da educação. Campinas: Autores Associados, 1995.

CUNHA, Eleonora Schettini M.; THEODORO, Hidelano Delanusse (Orgs.). Desenho institucional, democracia e participação: conexões teóricas e possibilidades analíticas. Belo Horizonte: D'Plácido, 2014

GOHN, Maria da Glória. Conselhos gestores e participação sociopolítica. São Paulo: Cortez, 2001.

. O novo associativismo e o Terceiro Setor. Serviço Social \& Sociedade, São Paulo, v. 19, n. 58, p. 9-23, nov. 1998.

GURGEL, Claudio; JUSTEN, Agatha. Controle social e políticas públicas: a experiência dos Conselhos Gestores. Revista de Administração Pública, Rio de Janeiro, v. 47, n. 2, p. 357-378, mar./abr. 2013.

KLEBA, Maria Elisabeth; MATIELO, Alexandre; COMERLATTO, Dunia; RENK, Elisonia; COLLISELLI, Liane. O papel dos conselhos gestores de políticas públicas: um debate a partir das práticas em conselhos municipais de Chapecó (SC). Ciência e Saúde Coletiva, Rio de Janeiro, v. 15, n. 3, p. 793-802, 2010.

LAVALLE, Adrian Gurza; HOUTZAGER, Peter P.; CASTELLO, Graziela. Representação política e organizações civis: novas instâncias de mediação e os desafios da legitimidade. Revista Brasileira Ciência e Sociedade, São Paulo, v. 21 , n. 60 , p. 43-66, fev. 2006.

LIMA, Antônio Bosco de; VIRIATO, Edaguimar Orquizas. As políticas de descentralização, participação e autonomia: desestatizando a educação pública. In: REUNIÃO ANUAL DA ANPED, 23., 2000, Caxambú. Anais... Rio de janeiro: ANPED, 2000. p. 187-206.

LUCHMANN, Lígia Helena Hahn. A representação no interior das experiências de participação. Lua Nova: Revista de Cultura e Política, São Paulo, n. 70, p. 139-170, 2007. 


\section{movimento \\ faculdade de educação - programa de pós-graduação em educação \\ universidade federal fluminense issn 2359-3296 \\ ano 3 número 5 - 2016}

MALPICA, Carlos Faustor. Descentralización y planificación de la educación: experiências recientes en países de América Latina. Paris: Unesco/IIPE, dic. 1994 (Informe de Investigación, 102).

MARTINS, Ângela Maria (Org.). Estado da Arte: gestão, autonomia escolar e órgãos colegiados (2000/2008). Brasília: Liber; Niterói: Anpae, 2011.

MARTINS, Rosilda Baron. Escola Cidadã no Paraná: análise de seus avanços e retrocessos. Olhar de Professor, Ponta Grossa, n. 1, v. 1, p. 129-148, 1998.

MENASCE, Márcio. Governo publica lei aprovando eleições para diretores de escolas: Essa era uma das exigências do movimento 'Ocupa'. Disponível em: <http://oglobo.globo.com/rio/governo-publica-lei-aprovando-eleicoes-paradiretores-de-escolas-19449870>. Acesso em 14 nov. 2016.

MENDES, Denise Cristina Vitale Ramos. Representação política e participação: reflexões sobre o déficit democrático. Revista Katálysis, Florianópolis, v. 10, n. 2, p. 143-153, jul./dez. 2007.

MORESCHI, Elmari. Os conselhos municipais de educação: o caso do município de São José dos Pinhais. Tuiuti, 2010. 110 f. Dissertação (Mestrado em Educação) - Universidade Tuiuti do Paraná.

OLIVEIRA, Cleiton; GANZELI, Pedro; GIUBILEI, Sonia; BORGES, Zacarias Pereira. (Orgs.). Conselhos municipais de educação: um estudo na região metropolitana de Campinas. Campinas: Alínea, 2006.

OLIVEIRA, Izolde Hilgemberg de. Conselho municipal de educação de Ponta Grossa: aspectos históricos, funções e contribuições. Ponta Grossa, 2008. 115 f. Dissertação (Mestrado em Educação) - Universidade Estadual de Ponta Grossa.

OLIVEIRA, Virgílio Cézar da Silva e, PEREIRA, José Roberto; OLIVEIRA, Vânia A. R. de Os conselhos gestores municipais como instrumentos da democracia deliberativa no Brasil. Cadernos EBAPE.BR, Rio de Janeiro, v. 8, n. 3, p. 422437, set 2010.

PARENTE, Marta Maria; LÜCK, Heloísa. Mapeamento da descentralização da educação brasileira nas redes estaduais do ensino fundamental. Rio de Janeiro: Ipea, 1988. 


\section{movimento}

faculdade de educação - programa de pós-graduação em educação

universidade federal fluminense issn 2359-3296

ano 3 número 5 - 2016

PERONI, Vera. Política educacional e papel do estado no Brasil dos anos 1990. São Paulo: Xamã, 2003.

PIEROZAN, Sandra Simone Hopner. Um estudo dos conselhos municipais de educação, seus limites e possibilidades. Curitiba, 2006. 228 f. Dissertação (Mestrado em Educação) - Faculdade de Educação, Universidade Federal do Paraná.

PIEROZAN, Sandra Simone Hopner; GONÇALVEZ, Maria Dativa de Salles. Um estudo sobre os conselhos municipais de educação: razões, limites e possibilidades. In: SEMINÁRIO DE PESQUISA EM EDUCAÇÃO DA REGIÃO SUL, 6., 2006, Santa Maria. Anais... Santa Maria: ANPEd, 2006. 1 CD-ROM.

RIBEIRO, Darcy Marzulo; RAGGIO, Nádia Zaiczuk; KORNIN, Thaís; VERDE, Valéria Villa. A descentralização das políticas sociais no Paraná. Revista Paranaense de Desenvolvimento, Curitiba, n. 90, p. 31-51, jan./abr. 1997.

SANTOS FILHO, José Camilo dos. O recente processo de descentralização e de gestão democrática da Educação no Brasil. Revista Brasileira de Estudos Pedagógicos, Brasília, DF, v. 73, n. 174, p. 219-241, 1992.

SARMENTO, Diva Chaves. Criação dos sistemas municipais de ensino. Educação \& Sociedade, Campinas, v. 26, n. 93, p. 1.363-1.390, set./dez. 2005.

SAVIANI, Dermeval. Sistemas de ensino e planos de educação: o âmbito dos municípios. Educação \& Sociedade, Campinas, v. 20, n. 69, p. 119-136, dez. 1999.

SCHEINVAR, Estela; ALGEBAILE, Eveline. (Orgs.). Conselhos participativos e escola. Rio de Janeiro: DP\&A, 2005.

SOUZA, Donaldo Bello de. (Org.). Acompanhamento e controle social da educação: fundos e programas federais e seus conselhos locais. São Paulo: Xamã, 2006.

- (Org.). Conselhos municipais e controle social da educação: descentralização, participação e cidadania. São Paulo: Xamã, 2008.

. (Org.). Mapa dos Conselhos Municipais de Educação no Brasil. São Paulo: Loyola, 2013a. 


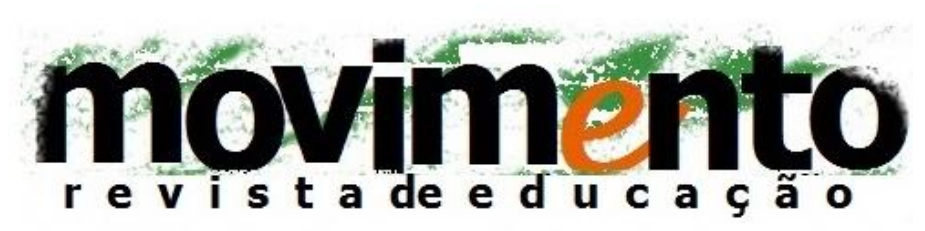

faculdade de educação - programa de pós-graduação em educação

universidade federal fluminense issn 2359-3296

ano 3 número 5 - 2016

Apresentação. In: . (Org.). Mapa dos Conselhos Municipais de Educação no Brasil. São Paulo: Loyola, 2013b, p. 11-17.

. Globalização: a mão invisível do mercado mundializada nos bolsões da desigualdade social. Boletim Técnico do SENAC, Rio de Janeiro, v. 22, n. 2, p. 3-11, maio/ago. 1996.

SOUZA, Donaldo Bello de; DUARTE, Marisa Ribeiro Teixeira; OLIVEIRA, Rosimar de Fátima. CMEs no Brasil: uma cartografia a partir dos estudos teóricoempíricos. In: SOUZA, Donaldo Bello de (Org.). Mapa dos Conselhos Municipais de Educação no Brasil. São Paulo: Loyola, 2013, p. 23-55.

SOUZA, Donaldo Bello de; FARIA, Lia Ciomar Macedo de. Reforma do estado, descentralização e municipalização do ensino no Brasil: a gestão política dos sistemas públicos de ensino pós-LDB 9.394/96. Ensaio: Avaliação e Políticas Públicas em Educação, Rio de Janeiro, v.12, n.45, p. 925-944, out./dez. 2004.

VALLE, Bertha de Borja Reis do; VASCONCELOS, Maria Celi Chaves. (Orgs.). Conselhos municipais de educação: organização e atribuições nos sistemas de ensino do estado do Rio de Janeiro: Quartet; Faperj, 2012. 